\title{
Pensamento Computacional nas Escolas: Limitado pela Tecnologia, Infraestrutura ou Prática Docente?
}

\author{
Maici Duarte Leite ${ }^{1,2}$, Francisco Reinaldo ${ }^{1}$, Eleandro Maschio², Diego Marczal ${ }^{2}$, \\ Carolina Moreira Oliveira ${ }^{2}$ \\ ${ }^{1}$ Departamento Acadêmico de Informática \\ Universidade Tecnológica Federal do Paraná (UTFPR) \\ Francisco Beltrão - PR - Brasil \\ ${ }^{2}$ Núcleo de Pesquisas no Ensino da Computação (NPEC) \\ Universidade Tecnológica Federal do Paraná (UTFPR) \\ Guarapuava - PR - Brasil \\ \{maicileite, reinaldo, eleandrom, marczal, cmoliveira\} @utfpr.edu.br
}

\begin{abstract}
Information technology converges for innovative processes involving automation for solving problems in any area where it is applied. For education, Computational Thinking incorporates technology in educational environments and promotes dynamism with their techniques when it comes to methods traditionally used. This article identified the demands of some public schools in Southwest of Paraná, in aspects involving the use of technology as a means of transmission and acquisition of knowledge by learner and teacher. The results showed that the teaching and learning processes need to be urgently rebuilt. The intervention of students in Informatics becomes necessary in education activities related to computing in public schools.
\end{abstract}

Resumo. A informática converge para inovações e automatização de processos na resolução de problemas aplicada a quaisquer áreas. O Pensamento Computacional incorpora inovações tecnológicas no meio pedagógico e promove o dinamismo nas técnicas e métodos tradicionais. O artigo identificou as demandas das escolas municipais de Francisco Beltrão - Paraná, nos aspectos que envolvem o uso da tecnologia como meio de transmissão e aquisição de conhecimento, seja por parte do aprendiz ou do professor. Os resultados mostram reconstrução dos processos de ensino e aprendizagem. A intervenção de acadêmicos da Licenciatura em Informática é necessária no exercício docente relacionado à Computação nas escolas municipais.

\section{Introdução}

As novas tecnologias estão cada vez mais desafiando os professores em suas práticas docentes, pois o uso de smartphone e tablets em sala de aula já é um fato a ser considerado. Essa realidade presente em escolas públicas traz uma reflexão pertinente, ao uso do laboratório de informática perdendo espaço para a inserção dos recursos tecnológicos em sala de aula. Neste contexto, ações do governo no sentido de 
proporcionar novas formas de integrar o processo educativo à tecnologia e priorizar a aquisição de conhecimentos (Fiorio, 2014). Essas são ações afirmativas para alavancar o ensino com lousas digitais e tablets para professores, oficinas de robótica e oficinas de introdução a programação.

O dinâmico contexto educacional elege os dispositivos móveis como uma ferramenta para auxiliar o professor a promover no aluno sua aprendizagem, autonomia, criticidade e criatividade. Contudo, torna-se prioritário que o professor assuma o papel de mediador da interação entre a tríade aluno, conhecimento e computador. Infelizmente, o que se observa na prática escolar é a falta de interesse do professor para o exercício deste papel (Reinaldo, 2016). Também são poucas as escolas que possuem suficientes dispositivos móveis a contemplar um por aluno, ou mesmo que contemplam metodologias de ensino diferenciadas na prática docente.

A atualização curricular dos professores está sendo fortemente consolidada por programas do governo para o uso de recursos tecnológicos em sala de aula (PARFOR e ProInfo) ${ }^{1}$. Também, os cursos de Licenciatura em Informática uniram-se às escolas através do Programa Institucional de Bolsa de Iniciação à Docência (PIBID) para oferecer oficinas tecnológicas e minicursos. Percebe-se que há é uma força-tarefa dos governos federal, estadual e municipal no sentido de inserir em definitivo a tecnologia num ambiente escolar ainda acanhado, seja pelo preparo dos professores em relação aos recursos tecnológicos, seja pela inserção dos alunos de licenciatura em atividades direcionadas a estágios que propiciam experiência enquanto docente.

A explicação para a resistência dos professores ao uso da tecnologia pode estar fundamentada no paradigma dos currículos tradicionalistas. Trata-se de uma vertente contrária à vaga curricular para professor graduado em Licenciatura em Informática. Desta maneira, o conceito de Pensamento Computacional, proposto por Wing (2006), emergiu como incentivador aos recursos tecnológicos utilizados por professores das escolas públicas municipais da região de Francisco Beltrão - Paraná, que não tem a formação tecnológica inserida em seus currículos.

O objetivo deste trabalho foi identificar e mapear itens presentes no espaço de intervenção para compreender se a aplicação da proposta do Pensamento Computacional nas escolas municipais está limitada à tecnologia ou ao currículo dos professores. Para isso, os alunos da disciplina de Didática Aplicada à Informática estruturaram um survey que foi aplicado em escolas municipais de Francisco Beltrão - Paraná. Esta atividade fez parte dos Estágios I, II e III de experimentação à Prática Docente dos acadêmicos. Os resultados apontaram para um colegiado ainda não preparado e sem vistas de interesse tecnológico.

\section{Pensamento Computacional e o Curso de Licenciatura em Informática}

Pensamento Computacional é um tema que atrai pesquisadores e parece estar impactando no contexto escolar. Em 2006, Jeannette M. Wing, no artigo Computational Thinking, apresenta o conceito para Pensamento Computacional e a relevância de abordar tal assunto dentro do contexto educacional de forma tão elementar quanto o aprendizado da

${ }^{1}$ Plano Nacional de Formação de Professores (PARFOR) e Programa Nacional de Tecnologia Educacional (ProInfo). 
leitura, escrita ou de operações matemáticas. Deste ponto em diante, diversas pesquisas e aplicações do Pensamento Computacional foram estudadas e aplicadas.

O termo Pensamento Computacional, termo cunhado pela proposta de Jeannette Wing, está também associado às ideias de resolução de problemas, projeto de sistemas e compreensão do comportamento humano norteados por conceitos fundamentais da Ciência da Computação (Wing, 2006). Isto se revela como um método utilizado para solucionar problemas, conceber sistemas pelo tal como preconiza a Teoria Geral de Sistemas pela habilidade de abstrair e generalizar, e compreender o comportamento humano inspirado em conceitos fundamentais da Ciência da Computação.

Araujo, Andrade e Serey (2015) se posicionam a partir da definição dada pela International Society for Technology in Education (ISTE) e pela Computer Science Teachers Association (CSTA) como uma abordagem para resolução de problemas, incorporando processos mentais e ferramentas que utilizam habilidades como organização e análise de dados, construção de algoritmos, abstração, criação de modelos, simulação, automatização de soluções e paralelização, considerando como uma lista de habilidades. Nessa mesma perspectiva, França e Tedesco (2015) defendem a inserção do Pensamento Computacional desde a educação básica como forma de melhorar o aprendizado lógico em nível escolar dos alunos e possibilitar o uso mais eficaz dessas tecnologias móveis em benefício da sociedade.

É importante lembrar que o Pensamento Computacional não se fundamenta em saber navegar na Internet, acessar e-mails, editar um texto, utilizar planilhas eletrônicas, elaborar uma apresentação ou manipular um equipamento eletrônico. Sua importância está para o processo de resolução de problemas lógicos nos diversos contextos da sociedade, permitindo que se possa aplicar a Computação nas suas ações cotidianas (GOMES e MELO, 2013).

Segundo Mestre et. al. (2015), as habilidades estimuladas pelo Pensamento Computacional estão diretamente relacionadas à resolução de problemas, que envolvem as capacidades de ler, interpretar textos, compreender situações reais propostas e transpor informações para modelos matemáticos, científicos ou sociais. Para os autores Araújo, Andrade, Guerrero (2015), o Pensamento Computacional é um conjunto de conceitos, habilidades e práticas da Computação que podem ser aplicados tanto em atividades do cotidiano como em outras áreas do conhecimento. Uma abordagem de resolução de problemas incorporando processos mentais e ferramentas que utilizam habilidades, tais como organização e análise de dados, construção de algoritmos, abstração, decomposição, simulação, automatização e paralelização.

O Pensamento Computacional está centrado na perspectiva da resolução de problemas mediados ou não pelo uso computador. Essa abordagem se expande por todos os contextos na busca de soluções mais eficientes para resolver problemas e atividades complexas.

Nunes (2010) esclarece que o ensino de aplicativos, tais como editores de texto, planilhas de cálculo, linguagens de programação não influencia pensamentos de resolução de problemas na educação básica. Por exemplo, para datilografar não é necessário o uso de um editor de texto, nem calculadoras para o ensino da Matemática. $\mathrm{O}$ papel do professor está em tornar o aluno confiante e capaz de pensar 
computacionalmente. Para Blikstein (2008), o uso dos aparatos digitais (gadget) também é um facilitador a desenvolver a habilidade do Pensamento Computacional.

Os cursos de Licenciatura em Informática têm a responsabilidade de formar professores para disseminar o Pensamento Computacional, assim se pode confirmar a demanda em relação as competências e habilidades previamente definidas no Processo $\mathrm{n}^{\circ}$ 23001.000026/2012-95 do tratado pelas Diretrizes Curriculares Nacionais para os cursos de graduação (bacharelado e licenciatura) em Computação necessárias para aquisição de conhecimentos de forma autônoma e efetiva (NUNES, 2011). O aluno deve atingir competências para reconhecer tarefas a serem realizadas de maneira mais rápida $\mathrm{e}$ eficientemente mediadas por computador. A partir dessas competências, o aluno também será capaz de desenvolver habilidades para programar o computador a realizar tais tarefas.

Portanto, ao se propor a discussão do referido tema dentro do curso de Licenciatura em Informática, pensou-se em posicionar os futuros profissionais em seus futuros comprometimentos, enquanto sujeito responsável para atuar no ensino e exercitar sua prática de docente. Nesse sentido, considerou-se o posicionamento de Blikstein (2008) para suprir as necessidades da formação de professores mediante as exigências da sociedade e suas transformações tecnológicas.

\section{Metodologia}

Para elucidar se o uso do Pensamento Computacional nas escolas municipais está limitado à tecnologia, infraestrutura ou ao currículo dos professores das escolas da rede pública municipal, utilizou-se do survey exploratório supervisionado, como metodologia de coleta de dados amplamente empregada por Bauer e Gaskell (2002).

Foram selecionadas, de maneira aleatória, 21 escolas públicas municipais, sendo 5 escolas rurais, ambas na região do município de Francisco Beltrão - Paraná. As escolas são compostas por alunos em sua maioria pertencentes às classes socioeconômicas $\mathrm{B}$ e $\mathrm{C}$, com acesso a computadores na residência, na escola ou ambas. Cada escola teve um professor que participou da pesquisa em sua função de coordenador pedagógico ou diretor escolar, em idade de 31 a 55 anos, possuindo entre 4 e 21 anos de magistério, e pertence à mesma área de concentração dos professores da escola. Todos os participantes possuem currículos tradicionais. Tantos os participantes da pesquisa quanto os demais professores das escolas têm acesso ao computador na residência e na escola.

Obedecendo os princípios éticos da Declaração de Helsinki, as 18 questões predeterminadas buscavam por indicativos de deficiência em quatro dimensões, sendo (i) Infraestrutura e Equipamentos Informáticos, (ii) Acesso à Internet nas Salas de Aulas, (iii) Ferramentas e Programas mais utilizados nas Salas de Informática, (iv) Internet vs. Atividades Escolares.

\section{Resultados}

No que tange à primeira dimensão, intitulada Infraestrutura e Equipamentos Informáticos, ver Figura 1, nota-se que somente $60 \%$ das escolas apresentam computadores em condições para a prática computacional. Este resultado permite aplicar o Pensamento Computacional uma vez que a infraestrutura se encontra coerente. 
VI Congresso Brasileiro de Informática na Educação (CBIE 2017)

Anais dos Workshops do VI Congresso Brasileiro de Informática na Educação (WCBIE 2017)

Condições de infraestrutura e equipamentos das salas de informática.

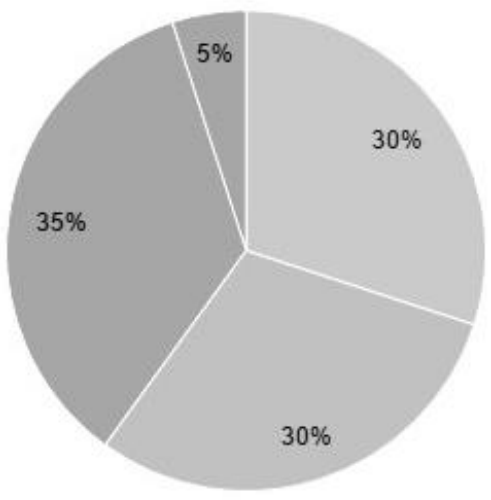

Razoável infra-estrutura: computadores antigos, porém funcionando.

Boa infraestrutura:

computadores novos e sala bem montada.

Computadores antigos e sala em condições precárias.

A escola não possui sala de computadores (somente existe na biblioteca).

Figura 1. Condições da infraestrutura e equipamentos das salas de informática

Para a segunda dimensão, intitulada Acesso à Internet nas Salas de Aulas, a Figura 2 apresenta um resultado que favorece a argumentação daqueles professores tradicionalistas que usam quadro e giz. Embora dados revelaram que mais de 50\% das escolas não possuem acesso à Internet, ainda assim é possível reverter a situação e planejar ações que permitam explorar o Pensamento Computacional sem o uso dos artefatos computacionais.

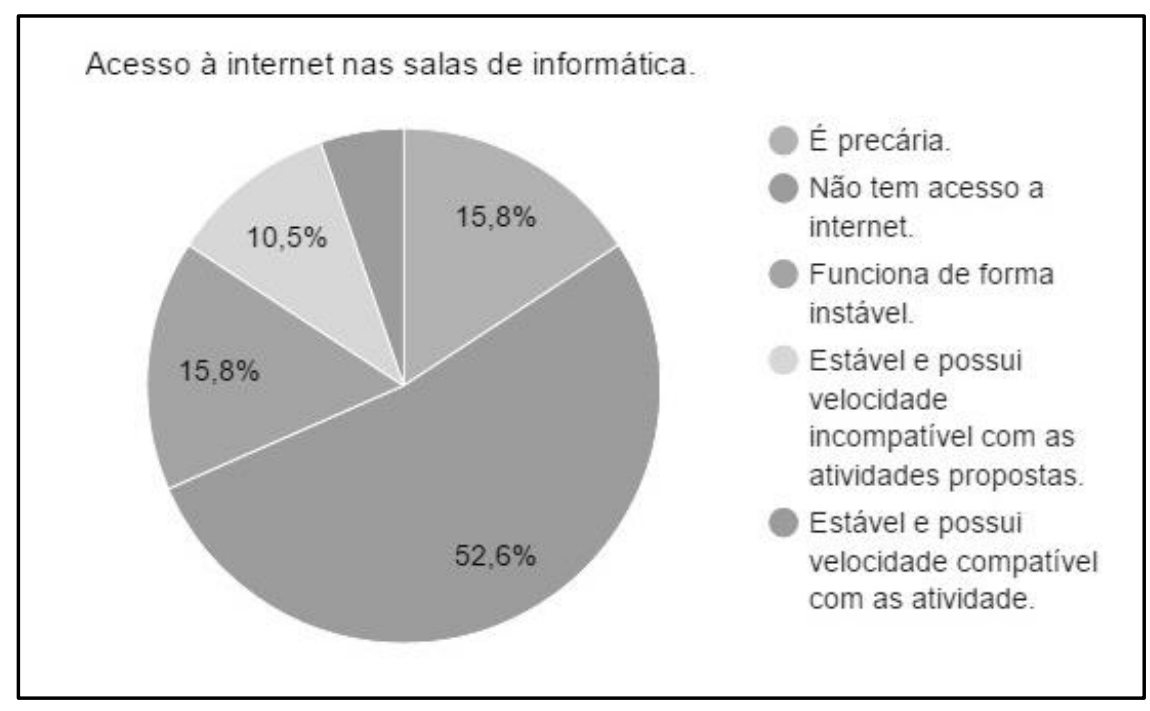

Figura 2. Acesso à Internet das salas de informática

Já a terceira dimensão, chamada de Ferramentas e Programas mais utilizados nas Salas de Informática, revelou que embora as escolas não possuírem acesso constante à Internet, alguns professores utilizaram do Pensamento Computacional no uso de softwares educativos e utilitários, conforme apresenta a Figura 3. 
VI Congresso Brasileiro de Informática na Educação (CBIE 2017)

Anais dos Workshops do VI Congresso Brasileiro de Informática na Educação (WCBIE 2017)

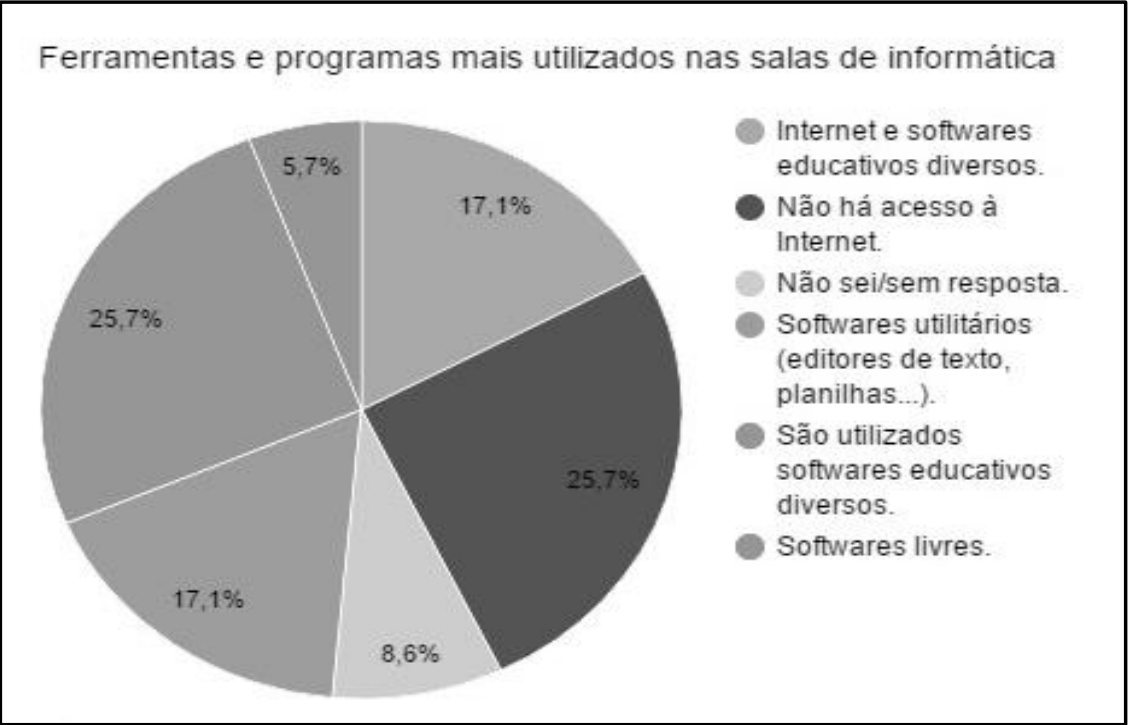

Figura 3. Ferramentas e programas utilizados nas salas de informática

Por fim, a última dimensão, intitulada Internet vs. Atividades Escolares, apresenta dados que informam o desinteresse dos alunos frente às atividades desenvolvidas nas salas de informática com metodologias tradicionalistas, ver Figura 4. Estes dados também revelaram que os softwares educativos não estão sendo trabalhados de maneira se fazer presente nas atividades cotidianas dos alunos. Infelizmente infere-se que o uso das salas de informática está somente pela manipulação de objetos, sem um motivo ou aplicação direta ao Pensamento Computacional em seu cotidiano escolar.

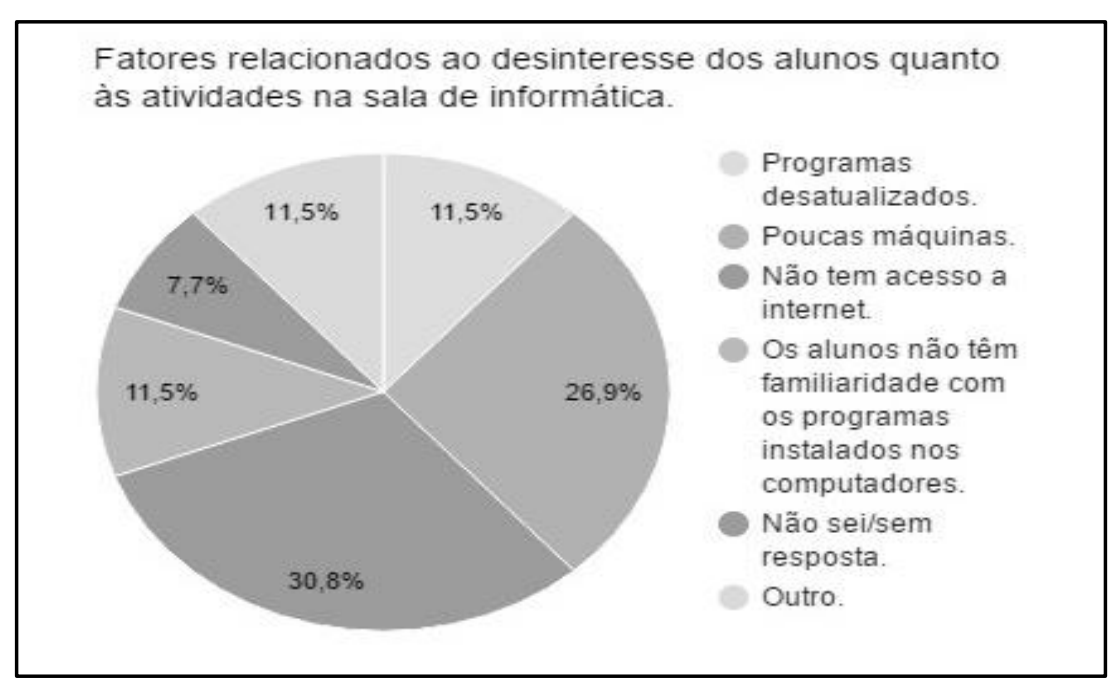

Figura 4. Gráfico dos fatores relacionados ao desinteresse dos alunos quanto às atividades na sala de informática

Os resultados encontrados apontam evidências de atividades abordadas com pouca complexidade, tais como ler notícias, copiar conteúdos, visualizar mapas, desenhar, escrever com editores de texto, calcular com calculadora. A partir desses dados é possível afirmar que a forma como a tecnologia foi explorada por estas escolas não satisfaz a perspectiva do Pensamento Computacional. 
VI Congresso Brasileiro de Informática na Educação (CBIE 2017)

Anais dos Workshops do VI Congresso Brasileiro de Informática na Educação (WCBIE 2017)

\section{Conclusões}

O estudo abordou a questão fundamental sobre a preparação dos professores e das estruturas educacionais para a implementação do ensino de computação. Também descreveu os resultados obtidos com a aplicação de um survey em escolas públicas com o objetivo de compreender como o Pensamento Computacional está sendo tratado nas escolas e quais as limitações existentes. Basicamente, o survey contemplou as seguintes dimensões: infraestrutura, acesso à Internet, aplicativos e atividades escolares. Os resultados mostraram um corpo docente despreparado para atuar com a prática do pensamento computacional.

Com o objetivo de identificar se a aplicação do Pensamento Computacional estava limitada pela infraestrutura ou pelos professores, percebeu-se que todo o processo de ensino-aprendizagem precisa ser considerado. Embora se tenha espreitado apenas as atividades escolares que usam computador ou dispositivos móveis, é sabido que a aplicação do Pensamento Computacional vai além. Nessa vertente, o mapeamento nas escolas revelou que o esforço do governo em investir em formação de professores para uso de recursos tecnológicos é válido, mas parece frágil. Assim, cognição e comportamento podem ser relacionados, extraíndo as melhores características, com o intuito de revelar um método para solucionar problemas. De posse dessa hibridização, é possível conceber sistemas tal como preconiza a Teoria Geral de Sistemas e sua habilidade de abstrair, generalizar e compreender o comportamento humano inspirado em conceitos fundamentais da Ciência da Computação. No caso das escolas presentes neste estudo, ainda há muito aspectos a serem reforçados, validados pelos resultados encontrados na região Sudoeste do Paraná. Possivelmente seja a consequência do currículo tradicionalista destes professores em não pensar computacionalmente, de maneira lúdica ou ainda, da proposta não ter sido esclarecida junto às escolas, através de cursos de formação de professores, ou da demanda de um licenciado em informática estar presente nestes espaços.

A análise dos dados também revelou que embora haja nas escolas permissão de uso aos tablets, smartphones e acesso à Internet, as práticas docentes estão aquém das habilidades e competências dos alunos. Isso permite inferir que ainda prevalece a cultura do quadro e giz para a resolução de problemas, tornando a escola uma custosa lan house para o governo, mas com forte potencial para atender a demanda do ensino-aprendizagem. Os recursos tecnológicos quando aplicados de forma correta e lúdica tendem a motivar e alavancar a aquisição do conhecimento, expandindo-se para além dos espaços escolares.

Vale destacar que o uso dos recursos tecnológicos no ensino, não exige apenas seu manuseio, mas um interesse intrínseco em fazer a diferença na prática pedagógica reflexiva, uma vez que o uso de tablets e smartphones não garante, por si só, uma melhor qualidade do ensino. Em se tratando de tecnologia, a maneira como está sendo utilizada com os alunos mostra que é preciso uma grande intervenção dos profissionais de licenciatura para potencializar o uso do pensamento computacional (não necessariamente apenas com a internet, mas com outros recursos). Assim, a formação continuada de professores para a utilização de tecnologias afins pode vir a contribuir para o 
aprimoramento da prática educativa, se pautada pela compreensão das possibilidades e limites desse instrumento e na concretização do papel educativo escolar.

A análise dos gráficos também revelou um contexto escolar público bimodal. De um lado, professores e suas disciplinas específicas devem receber formação para explorar os recursos tecnológicos em sala de aula, uma vez que o governo não optou pela computação desplugada por Bell, Witten e Fellows (2011). De outro, os profissionais licenciados em informática buscam solidificar sua prática e sua participação no contexto escolar envoltos no Pensamento Computacional produto de uma formação preocupada com a pesquisa que emerge neste meio.

\section{Referências}

Araujo, A. L.; Andrade, W.; Serey, D. (2015). Pensamento Computacional sob a visão dos profissionais da computação: uma discussão sobre conceitos e habilidades. In Anais dos Workshops do Congresso Brasileiro de Informática na Educação (Vol. 4, p. 1454). doi:10.5753/cbie.wcbie.2015.1454

Bauer, M. W.; Gaskell, G. (2002). Pesquisa Qualitativa com Texto, Imagem e Som (5th ed.).

Bell, T., Witten, I. H. Fellows, M. (2011). Computer Science Unplugged: ensinando ciência da computação sem o uso do computador. Autoria própria. Acessado por http em csunplugged.org/wp-content/uploads/2014/12/CSUnpluggedTeachersportuguese-brazil-feb-2011.pdf

Blikstein, P. (2008). O pensamento computacional e a reinvenção do computador na educação. Disponível em < http://www.blikstein.com/paulo/documents/online/ ol_pensamento_computacional.html > Acesso em: 05 de mai. de 2016.

Fiorio, R., Esperandim, R. J., Silva, F. A., Varela, P. J., Leite, M. D., \& Reinaldo, F. (2014). Uma experiência prática da inserção da robótica e seus benefícios como ferramenta educativa em escolas públicas. III Congresso Brasileiro de Informática Na Educação (CBIE 2014). XXV Simpósio Brasileiro de Informática Na Educação (SBIE 2014), (Cbie), 1223-1232. http://doi.org/http://dx.doi.org/10.5753/cbie.sbie.2014.1223

França, R.; Tedesco, P. (2015). Desafios e oportunidades ao ensino do pensamento computacional na educação básica no Brasil. In Anais dos Workshops do Congresso Brasileiro de Informática na Educação (CBIE 2015) (Vol. 4, p. 1464). doi:10.5753/cbie.wcbie.2015.1464

Gomes, T. C. S.; e De Melo, J. C. B. (n.d.). O Pensamento Computacional no Ensino Médio: Uma Abordagem Blended Learning. In Workshop sobre Educação em Computação (WEI 2013), 2013, Maceió, AL. Anais do XXXIII Congresso da Sociedade Brasileira de Computação (CSBC 2013)

Mestre, P., Andrade, W., Guerrero, D., Sampaio, L., Rodrigues, R. D. S., \& Costa, E. (2015). Pensamento Computacional: Um estudo empírico sobre as questoes de matemática do PISA. In Anais dos Workshops do Congresso Brasileiro de Informática na Educação (Vol. 4, p. 1281). doi:10.5753/cbie.wcbie.2015.1281 
VI Congresso Brasileiro de Informática na Educação (CBIE 2017)

Anais dos Workshops do VI Congresso Brasileiro de Informática na Educação (WCBIE 2017)

Nunes, D. J. (2011). "Ciência da Computação na Educação Básica”. Jornal da Ciência. 09 de setembro

Reinaldo, F., Magalhães, D., Reis, L., Gaffuri, S., Freddo, A., \& Hallal, R. (2016). Uso de Smartphones na Educação: Avaliação por Grupos Focais. v. 1 (2016): Atas Investigação Qualitativa em Educação CIAIQ2016, 1(0).

Soares De França, R., Afonso, V., Ferreira, S., Cardoso, L., De Almeida, F., \& Costa Do Amaral, H. J. (2014). A disseminação do pensamento computacional na educação básica: lições aprendidas com experiências de licenciandos em computação.

Wing, J. (2006). Computational thinking. Commun. ACM, 49. 